Have received research grants (not current) from the British Society for Rheumatology, who received the funds from Abbive, Pfizer and UCB. Have received research grant (current) from the British Society for Rheumatology, who received the funds from Celgene., Florenzo lannone Consultant for: $F$ lannone has received consultancy fees and/or speaker honoraria from Pfizer, AbbVie, MSD, BMS, Novartis, Lilly, UCB outside this work, Speakers bureau: $F$ lannone has received consultancy fees and/or speaker honoraria from Pfizer, AbbVie, MSD, BMS, Novartis, Lilly, UCB outside this work, Lise Hyldstrup: None declared, Niels Steen Krogh: None declared, Mikkel Ǿstergaard Grant/research support from: Abbvie, Celgene, Centocor, Merck, Novartis, Consultant for: Abbvie, BMS, Boehringer-Ingelheim, Celgene, Eli Lilly, Hospira, Janssen, Merck, Novartis, Novo, Orion, Pfizer, Regeneron, Roche, and UCB, Speakers bureau: Abbvie, BMS, Boehringer-Ingelheim, Celgene, Eli Lilly, Hospira, Janssen, Merck, Novartis, Novo, Orion, Pfizer, Regeneron, Roche, and UCB, Merete L. Hetland Grant/research support from: BMS, MSD, AbbVie, Roche, Novartis, Biogen, Pfizer, Consultant for: Eli Lilly, Speakers bureau: Orion Pharma, Biogen, Pfizer, CellTrion, Merck, Samsung Bioepis DOI: 10.1136/annrheumdis-2019-eular.1800

\section{AB0753 COMPARING COMPOSITE MEASURES OF DISEASE ACTIVITY IN PSORIATIC ARTHRITIS: RESULTS FROM A RANDOMIZED PHASE 2 TRIAL WITH GUSELKUMAB}

${ }^{1}$ Philip Helliwell ${ }^{*}$, Atul Deodhar ${ }^{2}$, Alice B. Gottlieb ${ }^{3}$, Wolf-Henning Boehncke ${ }^{4}$, Xie L. Xu ${ }^{5}$, Stephen $\mathrm{Xu}^{5}$, Yuhua Wang ${ }^{5}$, Elizabeth C. Hsia ${ }^{5,6}$, Dafna D. Gladman ${ }^{7}$, Christopher T. Ritchlin ${ }^{8} .{ }^{1}$ University of Leeds, Leeds, United Kingdom; ${ }^{2}$ Oregon Health and Science Univ, Portland, United States of America; ${ }^{3}$ Icahn School of Med at Mount Sinai, New York, United States of America; ${ }^{4}$ Geneva University Hospitals and Dept of Pathology and Immunol, Geneva, Switzerland; 5 Janssen Research and Development, LLC, Spring House, United States of America; ${ }^{6}$ Univ of Pennsylvania, Phila, United States of America; ${ }^{7}$ University of Toronto, Krembil Research Institute, Toronto, Canada; ${ }^{8}$ University of Rochester Medical Center, Rochester, United States of America

Background: Psoriatic ArthritiS Disease Activity Score (PASDAS), GRAppa Composite scorE (GRACE) Index, modified Composite Psoriatic Disease Activity Index (mCPDAI), and Disease Activity Index for PSoriatic Arthritis (DAPSA) are composite indices recently developed to assess disease activity in psoriatic arthritis (PsA).1,2 Guselkumab (GUS) is a monoclonal antibody targeting interleukin-23 that has demonstrated efficacy in a phase 2 PsA trial.3

Objectives: To compare the effect of GUS on disease activity in psoriatic arthritis (PsA) as measured by these composite indices.

Methods: In this Phase- 2 trial, patients with active PsA $(>3$ tender, $>3$ swollen joints, C-reactive protein $\geq 3 \mathrm{mg} / \mathrm{L}, \geq 3 \%$ body surface area) were randomized 2:1 to subcutaneous GUS $100 \mathrm{mg}(n=100)$ or placebo (PBO, $\mathrm{n}=49$ ) at $\mathrm{Wk0}, \mathrm{Wk} 4$, and every 8 wks through Wk44. At Wk16, patients with $<5 \%$ improvement in swollen plus tender joints could early-escape (EE) to open-label ustekinumab. Patients continuing PBO crossed-over to receive GUS 100mg at Wks 24/28/36/44 (PBO to GUS). PsA composite indices PASDAS, GRACE, mCPDAI, and DAPSA were analyzed using lastobservation-carried-forward for missing/post-EE data through Week24. Instruments were validated using SF-36 physical component summary (PCS) score as an anchor. Sensitivity was assessed via standardized mean differences (SMDs), effect size (ES) and standardized response means (SRMs).

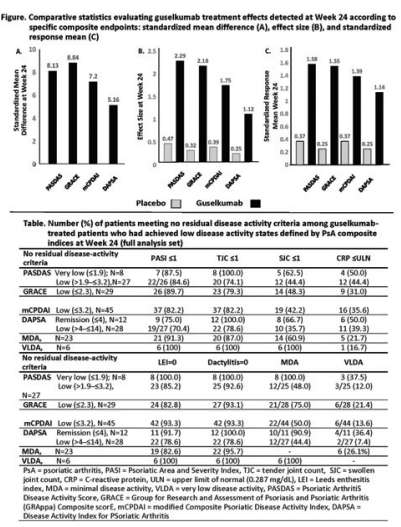

Results: Changes in SF-36 PCS score were consistent with disease activity states at Wk24 for each PsA composite index in guselkumab- treated patients. The SMD, ES and SRM indicated that guselkumab elicited a substantial effect in treating the diverse manifestations of PsA compared with placebo, regardless of composite index employed (Figure) PASDAS and GRACE indices appeared to be more sensitive than mCPDAI and DAPSA in detecting changes upon treatment and distinguishing guselkumab treatment effects relative to placebo. Residual disease activities among guselkumab-treated patients who achieved low disease activity at Week24 based on each PsA composite index are summarized in the Table.

Conclusion: Regardless of the PsA-specific composite index employed, GUS significantly improved disease activity and achieved clinically meaningful therapeutic targets such as low/minimal disease activity or remission. PASDAS and GRACE indices were more sensitive than mCPDAI and DAPSA in detecting changes in disease activity by guselkumab treatment.

\section{REFERENCES}

[1] Helliwell PS, et al. JRheumatol 2014;41:1212-1217.

[2] Scholes MM, et al. AnnRheumDis 2016;75:811-818.

[3] Deodhar A, et al. Lancet 2018;391: 2213-24.

Disclosure of Interests: Philip Helliwell Grant/research support from: Paid to charity: from AbbVie, Janssen and Novartis, Consultant for: Paid to charity: from AbbVie, Amgen, Pfizer, and UCB and Celgene. Paid to self: from Celgene and Galapagos, Atul Deodhar Grant/research support from: AbbVie, Amgen, Eli Lilly, GSK, Janssen, Novartis, Pfizer, and UCB, Consultant for: AbbVie, Amgen, BMS, Eli Lilly, Janssen, Novartis, Pfizer, and UCB, Alice B Gottlieb Grant/research support from: PI: Incyte Corporation, Janssen-Ortho Inc., Lilly ICOS LLC, Novartis, UCB, XBiotech, Consultant for: AbbVie, Dermira, Incyte Corporation, Lilly ICOS LLC, Novartis, Sun Pharmaceutical Industries Ltd., Avotres (unpaid), XBiotech (unpaid), Speakers bureau: AbbVie, Eli Lilly and Company, Janssen Biotech; advisory board: Bristol-Myers Squibb, Celgene Corporation, Janssen Biotech, Janssen-Ortho Inc., LEO Pharma, Novartis, UCB, Wolf-Henning Boehncke Consultant for: Pfizer Inc, Speakers bureau: Pfizer Inc, Xie $L \quad X u$ Employee of: Employee of Janssen Research \& Development, LLC, Stephen Xu Employee of: Employee of Janssen Research \& Development, LLC, Yuhua Wang Employee of: Employee of Janssen Research \& Development, LLC, Elizabeth C Hsia Employee of: Employee of Janssen Research \& Development, LLC, Dafna D Gladman Grant/research support from: AbbVie, Amgen, Celgene, Lilly, Novartis, Pfizer, and UCB, Consultant for: AbbVie, Amgen, BMS, Celgene, Galapagos, Gilead, Janssen, Lilly, Novartis, Pfizer, and UCB, Christopher T. Ritchlin Grant/research support from: AbbVie, Amgen, UCB Pharma, Consultant for: AbbVie, Amgen, Lilly, Novartis, Pfizer, UCB Pharma

DOI: 10.1136/annrheumdis-2019-eular.643

\section{AB0754 CLINICALLY MEANINGFUL IMPROVEMENT IN SKIN AND NAIL PSORIASIS IN BIO-NAÏVE ACTIVE PSORIATIC ARTHRITIS PATIENTS TREATED WITH INTRAVENOUS GOLIMUMAB: RESULTS THROUGH WEEK 52 FROM A PHASE-3 STUDY}

${ }^{1}$ M Elaine Husni", Philip J. Mease ${ }^{2}$, Soumya D. Chakravarty ${ }^{3,4}$, Shelly Kafka ${ }^{3}$ Diane D. Harrison ${ }^{5}$, Dennis Parenti ${ }^{3}$, Lilianne Kim ${ }^{5}$, Kim Hung Lo ${ }^{5}$, Elizabeth C. Hsia ${ }^{5,6}$, Arthur Kavanaugh ${ }^{7} .{ }^{1}$ Cleveland Clinic, Cleveland, United States of America; ${ }^{2}$ Swedish Med Center and U of Wash School of Med, Seattle, United States of America; ${ }^{3}$ Janssen Scientific Affairs, LLC, Horsham, United States of America: ${ }^{4}$ Drexel University College of Med, Philadelphia, United States of America; ${ }^{5}$ Janssen Research and Development, LLC, Spring House, United States of America; ${ }^{6}$ Univ of Penn Medical Center, Phila, United States of America; ${ }^{7}$ Univ of CA San Diego, San Diego, United States of America

Background: GO-VIBRANT is a Phase 3 trial of intravenous (IV) golimumab (GLM) in adult patients (pts) with active psoriatic arthritis (PsA) Clinically meaningful improvements in skin and nail psoriasis (PsO) and in Dermatology Life Quality Index (DLQI) that were significantly greater than placebo (PBO) at weeks (wks) 14 \& 24 were previously reported.1 Objectives: To evaluate improvement in skin and nail PsO and DLQI with IV GLM through wk52.

Methods: Adult bio-naïve PsA pts with active disease $(\geq 5$ swollen \& tender joints, CRP $>0.6 \mathrm{mg} / \mathrm{dL}$, active plaque psoriasis or documented history), despite treatment W/csDMARDs \&/or NSAIDs, were randomized to IV GLM $2 \mathrm{mg} / \mathrm{kg}$ at wks $0 / 4$ \& every 8 wks thereafter or PBO at wks $0 /$ $4 / 12 / 20$ with crossover to GLM at wk24. Pts with $\geq 3 \%$ body surface area (BSA) psoriasis at baseline (BL) were assessed using Psoriasis Area and Severity Index (PASI, $0-72$ ) of $75 / 90 / 100 \%$ improvement scale, 